\title{
Optimized Magnet wire size and Slot winding height for minimum AC losses in a Traction Machine
}

\author{
A. Bardalai, D. Gerada, Z. Xu, C. Gerada
}

\begin{abstract}
${ }^{\Phi}$ Abstract -- The demand for high performance electrical machines that combine high power density (kW/kg or $\mathrm{kW} / \mathrm{L})$, light - weighting and high efficiency have become more and more important in recent years. In these machines, mitigation of the parasitic losses associated with high - frequencies such as skin and proximity effect losses and circulating current losses due to flux leakage into slot become vital. This paper presents a methodology for selecting optimum magnet wire size and the slot winding height for minimum total loss (DC, Skin and Proximity, and Circulating current losses) in the concentrated winding of an interior permanent magnet machine using FiniteElememt approach.
\end{abstract}

Index Terms-- AC losses, conductors, high power density, optimization, permanent magnet machines, windings

\section{INTRODUCTION}

$T^{\mathrm{\mu}}$ automotive industry is going through an extraordinary transformation, with a major focus on vehicle electrification and this have intensified efforts in design and development of height performance electrical machines that combine high power density $(\mathrm{kW} / \mathrm{kg}$ or $\mathrm{kW} / \mathrm{L}$ ), light - weighting and high efficiency [1]. With the majority of the power loss within high power density electrical machines often being generated in the stator winding [2], it is necessary to reduce the copper losses and improve the heat transfer mechanisms for such losses. The main cause for winding failure is deterioration of insulation property. It is been reported that $30 \%$ of motor failures are due to insulation failure, $60 \%$ of which are caused by overheating. For every $10^{\circ} \mathrm{C}$ of additional heat to the windings, the insulation lifetime is halved [3]. Maximizing the slot filling offers a solution to reduce the DC cooper loss and achieve better thermal conductivity within the slot [4]. A general way to maximize the slot filling factor and achieve good thermal performance is to use rectangular conductors with higher cross - sectional areas and evenly laying them around segmented stator teeth in the form of preformed coils, coupled with the use of higher thermal conductivity materials [5]. However, the problem with the use of such bulky conductors in high frequency applications is that, the increase in apparent resistance of the windings is quite significant and the copper loss is many folds larger than the DC copper loss. Traditionally, to mitigate the loss associated with AC effects in bulk conductors, the solution is to split the

(1) Anuvav Bardalai, David Gerada, Zeyuan Xu and Chris Gerada are with Department of Electrical and Electronic, University of Nottingham, Nottingham, NG7 2RD, United Kingdom (e-mail: Anuvav.Bardalai@nottingham.ac.uk; David.Gerada@nottingham.ac.uk; Zeyuan.Xu@nottingham.ac.uk; Chris.Gerada@nottingham.ac.uk). large conductor cross - section into smaller sections using thin magnet wires connected in parallel. These magnet wires are then randomly inserted into the slot to fill up the slot area. However, the presence of slot flux - leakage, especially near the slot, give rise to the problem of uneven current sharing among the parallel strands or 'strands - in - hand' of a conductor and circulating currents. Various countermeasures such as the practice of not placing windings very close to slot openings exists [6] - [8].

Martin van der Geest in [9], showed that by placing the conductors towards the slot bottom, the total losses can be reduced, despite a decrease in slot filling factor. In [10], the authors presented an analysis of loss distribution and thermal conditions inside the slot using single conductor and 12 parallel strands model. The paper concluded that though the $\mathrm{AC}$ losses in the winding with higher number of parallel strands in greater than the solid conductor, the losses in the former model is more evenly distributed. Authors in [11], showed that by using rectangular flat wires in parallel teeth slot, the copper filling factor can be increased. The paper presented that by using the triangular free space between the two layers and the free area near the slot top for cooling pipes, the water jacket cooling can be removed and power density of the machine increased. However, at high frequencies the flat rectangular wires may incur significant loss and laying the rectangular flat wires flat across the slot causes manufacturing challenges and increase the production cost. Authors in [12], experimentally verified that by carefully controlling the shape of the bundles near the slot top, the AC losses can be significantly reduced.

As described in literature, for high power density a higher slot filling factor is desired. However, measured against AC effects deject higher fill factor. Therefore, for any given slot geometry, selection of an optimum strand diameter that satisfy both the need of higher fill factor and lower AC effects, combined with mechanical flexibility and ease of manufacturing become a process of paramount importance.

In this paper, using randomly - wound round magnet wires, a methodology to optimize the strand diameter and slot winding height for minimum losses in the winding is presented. Furthermore, it is shown that by optimizing the parameters such as the strand diameter, number of parallel strands and the winding height within the slot geometry, the total losses in the winding can be optimally minimized.

The paper is organised as follows: Section II introduces the high speed machine under investigation and the methodology used for analysis in this paper. In section III, some of the simulation results and analysis are presented. 


\begin{tabular}{cc}
\multicolumn{2}{c}{ TABLE I } \\
\hline \hline MACHINE PARAMETERS \\
\hline \hline Parameter & Specification \\
\hline Machine Type & Three - phase PMSM \\
Rotor type & Interior Flat \\
Magnet Material & N38EH \\
Peak power & $74 \mathrm{~kW}$ \\
Rated torque & $126 \mathrm{Nm}$ \\
Rated / maximum speed & $2800 / 10000 \mathrm{rpm}$ \\
Winding Type & Concentrated \\
Efficiency & $\geq 95 \%$ \\
Cooling Type & Water Jacket Cooling \\
Working Temperature & $-40 \sim 105^{\circ} \mathrm{C}$ \\
\hline \hline
\end{tabular}

Section IV compares the results presented in the former section and finally the conclusion is presented in section $\mathrm{V}$.

\section{MACHINE SPECIFICATION AND METHODOLOGY}

An existing high-speed traction machine, the details of which are listed in TABLE I, is used for the analyses in this paper.

\section{A. Selection of optimum strand diameter}

For computational efficiency, the same methodology for simplification of modelling described in [12] is used for analysis in this paper. That is, finite-element model is reduced to one slot pitch for faster computational time. Now, consider the geometry shown in Fig. 1, representing a slot of the electrical machine. The slot geometry has a woundable area (area which can be filled by the windings of the machine) marked by the four corners of the quadrilateral, $\mathrm{ABCD}$ and the height of the slot is H1. Here, the side $\mathrm{AB}$ being towards the slot top and side $C D$ being towards the back iron of the stator core. The slot area ABCD is filled with discs resembling magnet wire cross section (considering the insulation layer thickness and minimum gap between strands). Magnet wire strand sizes of grade 2 specification are chosen from an OEM of magnet wires [13]. The strand layout is shown in Fig. 1 with 'black' bordered discs representing the strands and the 'red' arrows representing the laying pattern of these discs. Varied diameter of the strands, from the smallest diameter available from the data of the OEM to the bulkiest strand that fits into the given slot

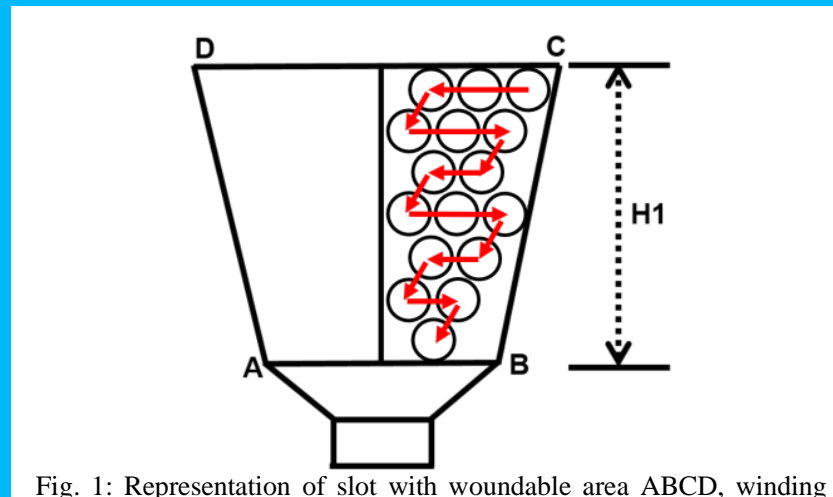
height $\mathrm{H} 1$ and horizontal strands layout

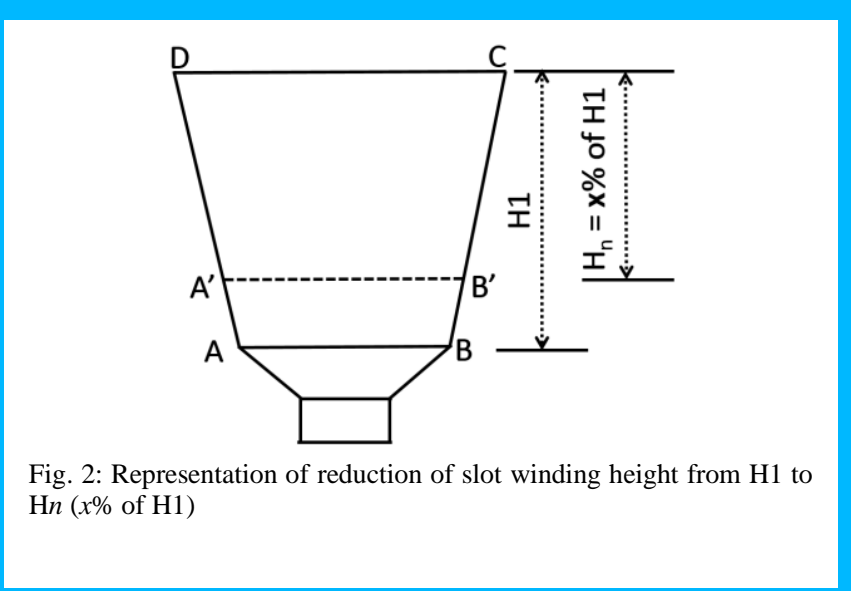

geometry and able to satisfy the minimum number of turns in the slot are considered. The changing insulation thickness with change in wire size is considered as well. Additional constraint is applied which accounts for the total strands in the slot to be divisible by the number of turns in the slot. The strand diameters those can satisfy all the conditions are stored.

\section{B. Selection of winding height}

After laying the strands in the slot geometry, the strands are clustered into bundles to resemble randomly-wound winding following a similar methodology described in [12]. With the purpose of selecting the optimum winding height, the winding is then pushed towards the slot bottom in steps. With $\mathrm{H} 1$ being the original winding height, the steps are chosen as percentage of height $\mathrm{H} 1$ and are as follows: $85 \%$, $75 \%, 65 \%$ and $55 \%$ of H1. Fig. 2 shows the representation of the reduced winding height of $\mathrm{H}_{n}$, where $\mathrm{H}_{n}$ is $x \%$ of $\mathrm{H} 1$. Reducing the winding height decreases the available winding area to a new area represented by the area of the quadrilateral A'B'CD as shown in Fig. 2. Then, the processes of selecting the optimum strand diameters and clustering into bundles are repeated for the new area (A'B'CD). As the area available for winding reduces, the strand diameters thus the available copper area reduces. This increases the DC loss while pushing the winding towards the slot bottom reduces the AC effects as described in the literature before. Thus, a critical height is reached where advancing the strands towards the slot bottom yields diminishing result of lower total loss in the winding as the DC loss overshadows the gain from reduction in AC losses.

\section{Finite - Element Analysis (FEA)}

For each slot height, strand diameters with high filling factor are selected and modelled for finite-element analysis (FEA). Careful considerations of skin depth and ease of manufacturability are made while selecting the strand diameter cases for modelling. These gives select number of plausible models. Similar methodology as described in [12] is used. The article shows accuracy of over $90 \%$ between FEA and experimental results. The modelling is carried out at the strand-level and the losses in the winding are analyzed for each selected case for a given slot height. Finite- Element software package Simcenter MAGNET from SIEMENS is used. The data is post processed and the maximum and minimum loss case for each slot height is then noted. 


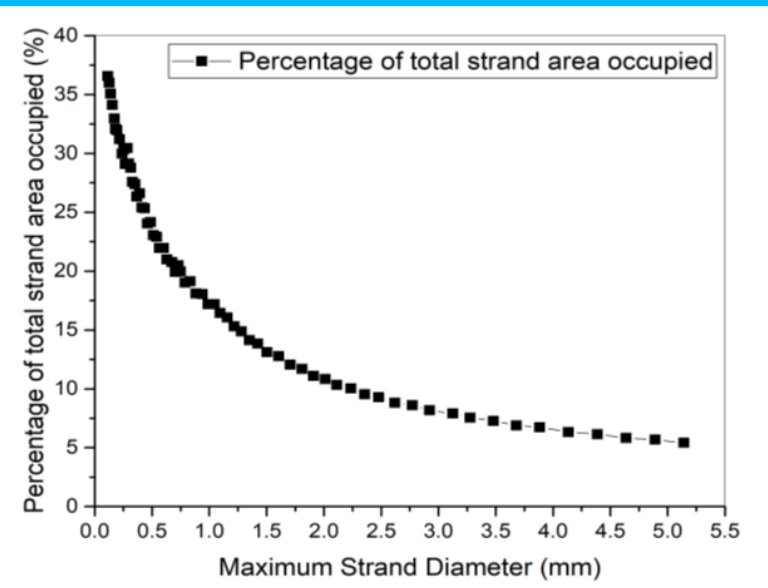

(a)

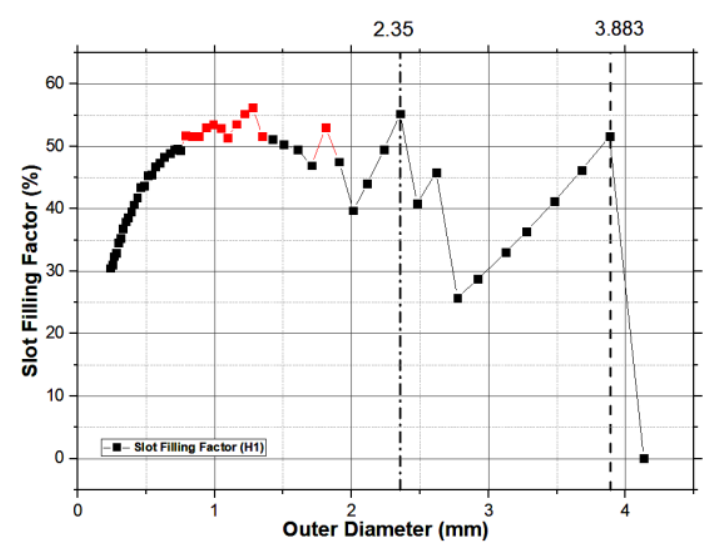

(b)

Fig. 3: (a) Percentage of total strand area occupied by the insulation coat (Grade 2), (b) Slot filling factor against the strand outer diameter for $\mathrm{H} 1$.

\section{SiMULATION RESULTS}

Since, AC losses are significant at the high frequencies, the FEA are carried out at a fundamental frequency of 666.67 $\mathrm{Hz}$ corresponding to machine speed of $10 \mathrm{krpm}$ and a rms current of $84 \mathrm{~A}$. The Total/DC loss ratio would be the highest at this speed.

For a selected slot height, the net slot (copper) filling factor is obtained across the entire magnet wire diameter range. Fig 3a shows the percentage of the total strand area occupied by insulation coat on the magnet wire with increasing in magnet wire diameter. On one extreme, for thinner wire size, the insulation covers more than $35 \%$ of the overall cross-section of the wire. While on the other end of the range, the insulation layer is just about $5 \%$ of the total cross-sectional area of the wire. In Fig. 3b, the slot filling plot against the magnet wire diameters of the strands for $\mathrm{H} 1$ is shown. Here, the 'Outer Diameter' in the abscissa includes the nominal diameter and the insulation thickness for the magnet wire size. For thinner magnet wires, the copper filling factor is low as the wires have large share of insulation thickness. As the wire size increase, the fill factor also increase till the wire size becomes large enough for the geometrical and other constraints to kick in. The data points marked in red are the points of interest as these strands provide higher filling factor, the diameters are well under the skin depth value at the fundamental frequency of $666.67 \mathrm{~Hz}$ and provide mechanical flexibility to wound around the teeth with relative ease. Apart from these strands size, the strands with diameters $2.35 \mathrm{~mm}$ (marked with dot dashed line) and $3.883 \mathrm{~mm}$ (marked by dashed line), produce higher fill factor. However, these sizes are either greater than the skin depth value or/and impair the advantage of flexibility provided by the thinner strands. Fig. 4 shows two of the models with height H1: (a) 5 parallel strands, (b) 11 parallel strands, (c) 18 parallel strands, and (d) 28 parallel strands. In the figure, different colours represent the turns of the coil and the disc of same colour represents the parallel strands or 'strands - in - hand'. TABLE II lists the losses in the winding of the machine for the models with slot height $\mathrm{H} 1$. In TABLE II, the column 'Total Loss in Active Length' presents the total losses in the active length of the winding of the machine models with varied parallel strands listed in the first column, 'Model with parallel strands'. The column titled, 'DC loss in Active Length', lists the DC loss in the active winding length calculated analytically and the column next, 'DC Loss in the end winding', lists the DC losses in the ending windings for models. In machines with mush winding with large number of strands-in-hand, the circulating current losses is the prominent contributor. Flux leakage into the slot is the main source of the circulating current losses and the effect in the ending winding is insignificant. Since, it is assumed that the significant AC losses occur only at the active winding length of the machine, the final column, 'Total loss', lists the Total loss (Total Active winding + DC end-winding loss) of the winding. The highest loss (approximately $1772 \mathrm{~W}$ ), is incurred in the active winding length of 11 parallel strands with Total / DC Loss of 4.61, i.e. the $\mathrm{AC}$ losses in the active length for this model is as high as 3.61 times the DC loss value. The minimum losses occur with 5 and 13 parallel strands models with Total / DC Loss ratio of 3.1 and 3.0 respectively.

Similarly, the above process is repeated for height $\mathrm{H} 2$ to H5. Fig. 5 shows one model for each of the height (H2 - H5).

\begin{tabular}{|c|c|c|c|c|c|c|}
\hline \multicolumn{7}{|c|}{$\begin{array}{l}\text { TABLE II } \\
\text { LOSSES IN THE WINDING OF THE MACHINE FOR H1 }\end{array}$} \\
\hline $\begin{array}{l}\text { Strand nominal } \\
\text { diameter }(\mathrm{mm})\end{array}$ & $\begin{array}{c}\text { Number of } \\
\text { parallel strands }\end{array}$ & $\begin{array}{c}\text { Total conductors } \\
\text { per slot }\end{array}$ & $\begin{array}{c}\text { Total Loss in } \\
\text { Active Length (W) }\end{array}$ & $\begin{array}{c}\text { DC loss in } \\
\text { Active Length }(\mathrm{W})\end{array}$ & $\begin{array}{c}\text { DC Loss in } \\
\text { the end winding }(\mathrm{W})\end{array}$ & Total loss (W) \\
\hline 1.7 & 5 & 100 & 1143.80 & 369.00 & 178.00 & 1321.80 \\
\hline 1.18 & 11 & 220 & 1604.31 & 348.12 & 168.00 & 1772.31 \\
\hline 1.06 & 13 & 260 & 1094.64 & 365.04 & 176.00 & 1270.64 \\
\hline 0.9 & 18 & 320 & 1310.54 & 365.76 & 176.00 & 1486.54 \\
\hline 0.71 & 28 & 560 & 1444.06 & 377.76 & 182.00 & 1626.06 \\
\hline
\end{tabular}




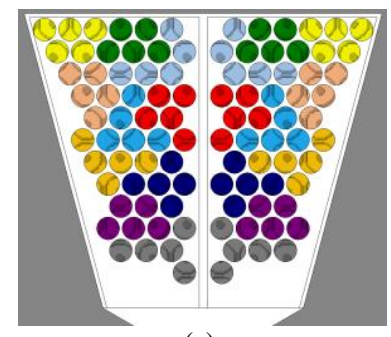

(a)

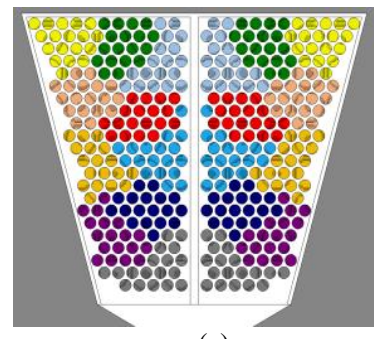

(c)

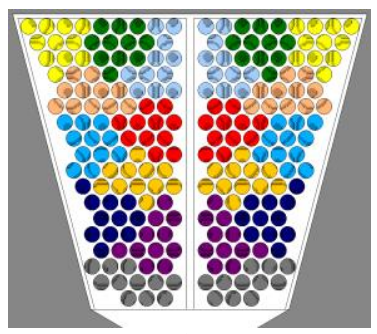

(b)

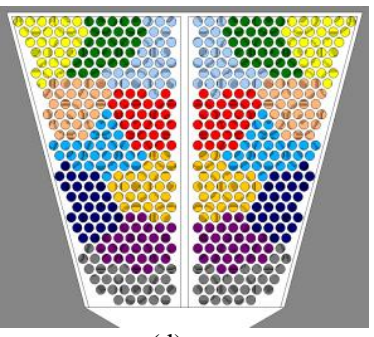

(d)
Fig. 4: Models used for analysis with height H1, (a) 5 parallel strands, (b) 11 parallel strands, (c) 18 parallel strands, and (d) 28 parallel strands

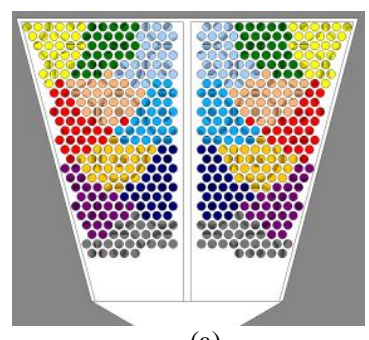

(a)

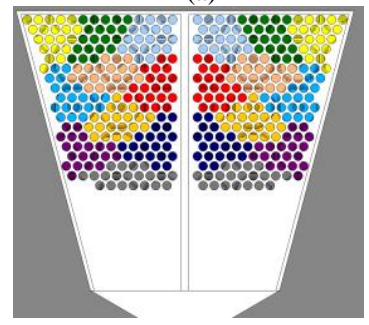

(c)

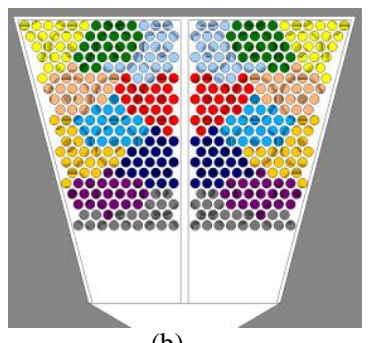

(b)

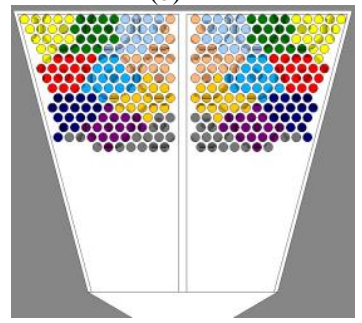

(d)
Fig. 5: Models used for analysis with height (a) H2, (b) H3, (c) H4, and (d) H4

\section{COMPARISON AND DISCUSSION}

\section{A. Maximum total loss for each slot winding height}

TABLE III lists comparison of losses in components for varying slot height (maximum total losses of each winding height). The models with maximum total losses in the winding for each slot height are selected for the comparison. Fig. 6 shows these comparisons of losses in graphical representation. As the slot height reduces in steps (from $\mathrm{H} 1$ to H5), the available copper area reduces and thus the DC losses in the winding increase. This can be seen by the steady increase of the DC losses in the active length and the endwinding regions of the winding represented by the 'red' and the 'blue' trace in the Fig. 6. However, with the reduction in

\section{TABLE III}

COMPARISON OF LOSSES IN COMPONENTS FOR VARYING SLOT HEIGHT (MAXIMUM TOTAL LOSSES OF EACH SLOT WINDING HEIGHT)

\begin{tabular}{lccccc}
\hline \hline Height & $\begin{array}{c}\text { Model } \\
\text { with } \\
\text { parallel } \\
\text { strands }\end{array}$ & $\begin{array}{c}\text { Active } \\
\text { length } \\
\text { Loss (W) }\end{array}$ & $\begin{array}{c}\text { DC loss } \\
\text { in active } \\
\text { length } \\
\text { (W) }\end{array}$ & $\begin{array}{c}\text { DC loss in } \\
\text { end- } \\
\text { winding } \\
\text { (W) }\end{array}$ & $\begin{array}{c}\text { Total } \\
\text { Loss } \\
\text { (W) }\end{array}$ \\
\hline \hline H1 & 11 & 1604.31 & 348 & 168 & 1772.31 \\
H2 & 27 & 1142.4 & 438 & 212 & 1354.4 \\
H3 & 7 & 1070.58 & 435 & 211 & 1281.58 \\
H4 & 10 & 905 & 531 & 257 & 1161.97 \\
H5 & 8 & 885.57 & 664 & 321 & 1206.78 \\
\hline \hline
\end{tabular}

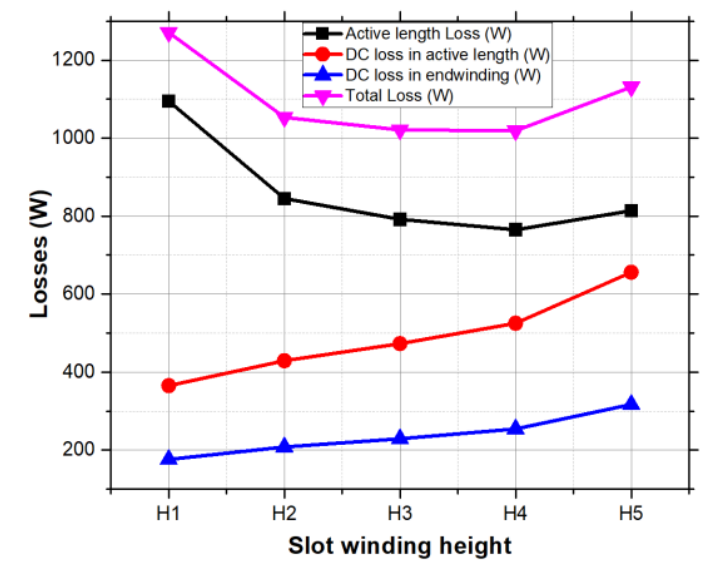

Fig. 7: Comparison of losses in components for varying slot heights (with minimum total losses from each winding height)

the winding slot height, the AC losses in the active length of the machine decrease markedly, which is represented by the 'black' trace in the figure. Therefore, the total losses in the winding reduces from height $\mathrm{H} 1$ till $\mathrm{H} 4$. For $\mathrm{H} 5$, although the losses in the active length reduces when compared to $\mathrm{H} 4$, the increase in DC losses overwhelms the net gain from the reduction of the $\mathrm{AC}$ losses in the active winding length and the total losses in the winding increases.

The slot winding height, $\mathrm{H} 4$, shows the minimum total losses for the comparison. From slot winding height $\mathrm{H} 1$ to $\mathrm{H} 4$, there is $53 \%$ increase in the DC losses at the endwinding region. However, the losses in the active length reduces by approximately $43 \%$ from $\mathrm{H} 1$ to $\mathrm{H} 4$, while the net reduction in the total losses in the winding for the same is approximately $34 \%$. Therefore, by optimising the slot winding height to $\mathrm{H} 4$, there is a net gain of $34 \%$ reduction in the total losses in the winding and approximately $28 \%$ empty area near towards (compared to the winding area of $\mathrm{H} 1$ ).

\begin{tabular}{|c|c|c|c|c|c|}
\hline \multicolumn{6}{|c|}{$\begin{array}{c}\text { TABLE IV } \\
\text { COMPARISON OF LOSSES IN COMPONENTS FOR VARYING SLOT HEIGHT } \\
\text { (MINIMUM TOTAL LOSSES OF EACH SLOT WINDING HEIGHT) }\end{array}$} \\
\hline Height & $\begin{array}{l}\text { Model } \\
\text { with } \\
\text { parallel } \\
\text { strands }\end{array}$ & $\begin{array}{l}\text { Active } \\
\text { length } \\
\text { Loss (W) }\end{array}$ & $\begin{array}{l}\text { DC loss } \\
\text { in active } \\
\text { length } \\
\text { (W) }\end{array}$ & $\begin{array}{l}\text { DC loss in } \\
\text { end- } \\
\text { winding } \\
\text { (W) }\end{array}$ & $\begin{array}{l}\text { Total } \\
\text { Loss } \\
(\mathrm{W})\end{array}$ \\
\hline H1 & 13 & 1094.64 & 365.04 & 176 & 1270.64 \\
\hline $\mathrm{H} 2$ & 22 & 845.05 & 429 & 208 & 1053.05 \\
\hline $\mathrm{H} 3$ & 10 & 791.79 & 473 & 229 & 1020.79 \\
\hline $\mathrm{H} 4$ & 9 & 764.72 & 525 & 254 & 1018.83 \\
\hline H5 & 10 & 813.66 & 656 & 317 & 1130.90 \\
\hline
\end{tabular}




\section{B. Minimum total loss for each slot winding height}

TABLE IV lists the comparison of the losses in the components for varying slot winding height (minimum total losses of each winding height). The models with minimum total losses in the winding for each slot winding height were selected for this comparison as shown in Fig. 7. Slot winding height, $\mathrm{H} 4$, has the minimum total losses where the losses in the active length of the winding reduces by approximately $30 \%$ when compared to $\mathrm{H} 1$, with a net reduction in the total losses in the winding of $19.8 \%$.

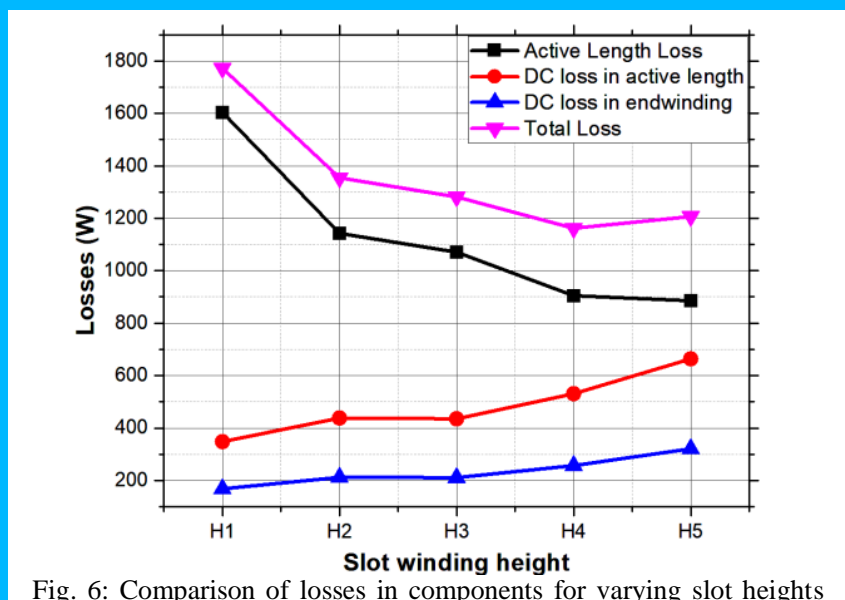
(with maximum total losses from each winding height)

\section{CONCLUSION}

This paper presented a methodology to reduce the high frequency losses in the winding of a concentrated winding interior permanent synchronous machine by optimising the magnet wire size and slot winding height. Using FE based models, it is shown that at the height, $\mathrm{H} 4$, which is $65 \%$ of the original height, $\mathrm{H} 1$, minimum total loss in the winding occur. This also allows for approximately $28 \%$ free space towards the slot opening. Therefore, by optimizing the winding height in the slot and selecting appropriate wire size, the total losses in the winding as well the net copper used can be significantly reduced. Further work on experimental verification is been planned and will be presented in future.

\section{REFERENCES}

[1] D. Gerada, A. Mebarki, N. L. Brown, C. Gerada, A. Cavagnino, and A. Boglietti, "High-Speed Electrical Machines: Technologies, Trends, and Developments," IEEE Transactions on Industrial Electronics, vol. 61, no. 6, pp. 2946-2959, 2014.

[2] D. Golovanov, L. Papini, D. Gerada, Z. Xu, and C. Gerada, "Multidomain Optimization of High-Power-Density PM Electrical Machines for System Architecture Selection," IEEE Transactions on Industrial Electronics, vol. 65, no. 7, pp. 5302-5312, 2018.

[3] P. Arumugam, "Design and modelling of permanent magnet machine's windings for fault-tolerant applications," University of Nottingham, 2013.

[4] A. M. EL-Refaie, "Fractional-Slot Concentrated-Windings Synchronous Permanent Magnet Machines: Opportunities and Challenges," IEEE Transactions on Industrial Electronics, vol. 57, no. 1, pp. 107-121, Jan 2010.

[5] R. Wrobel, P. H. Mellor, and D. Holliday, "Thermal Modeling of a Segmented Stator Winding Design," IEEE Transactions on Industry Applications, vol. 47, no. 5, pp. 2023-2030, 2011.
[6] G. J. Atkinson, B. C. Mecrow, A. G. Jack, D. J. Atkinson, P. Sangha, and M. Benarous, "The Analysis of Losses in High-Power FaultTolerant Machines for Aerospace Applications," IEEE Transactions on Industry Applications, vol. 42, no. 5, pp. 1162-1170, 2006.

[7] A. S. Thomas, Z. Q. Zhu, and G. W. Jewell, "Proximity Loss Study In High Speed Flux-Switching <newline/>Permanent Magnet Machine," IEEE Transactions on Magnetics, vol. 45, no. 10, pp. 4748-4751, 2009.

[8] S. Iwasaki, R. P. Deodhar, Y. Liu, A. Pride, Z. Q. Zhu, and J. J. Bremner, "Influence of PWM on the Proximity Loss in PermanentMagnet Brushless AC Machines," IEEE Transactions on Industry Applications, vol. 45, no. 4, pp. 1359-1367, 2009.

[9] M. van der Geest, H. Polinder, J. A. Ferreira, and D. Zeilstra, "Stator winding proximity loss reduction techniques in high speed electrical machines," in 2013 International Electric Machines Drives Conference, 2013, pp. 340-346.

[10] I. Petrov, M. Polikarpova, P. Ponomarev, P. Lindh, and J. Pyrhönen, "Investigation of additional AC losses in tooth-coil winding PMSM with high electrical frequency," in 2016 XXII International Conference on Electrical Machines (ICEM), 2016, pp. 1841-1846.

[11] M. Schiefer and M. Doppelbauer, "Indirect slot cooling for highpower-density machines with concentrated winding," in 2015 IEEE International Electric Machines Drives Conference (IEMDC), 2015, pp. $1820-1825$.

[12] A. Bardalai et al., "Reduction of Winding AC Losses by Accurate Conductor Placement in High Frequency Electrical Machines," in IEEE Transactions on Industry Applications, vol. 56, no. 1, pp. 183193, Jan.-Feb. 2020."Techinical data for winding wire," ed, 2016,

[13] URL:http://www.lww.se/wp-content/uploads/2017/06/LWWbrochure-2016.pdf.

Anuvav Bardalai (M'19) received the Ph.D. degree in high-speed electrical machines from the University of Nottingham, Nottingham, U.K., in 2019.

Dr. Bardalai's Ph.D. degree was focused on modeling, analyses, and mitigation of AC losses in high-frequency rotating electrical machines. Before joining Ph.D., he had a short stint in the industry. In 2020 he joined the PEMC group, University of Nottingham as Research Fellow. His research interests include design and analysis of high-speed electrical machines for applications related to traction and aerospace.

David Gerada received the Ph.D. degree in high-speed electrical machines from the University of Nottingham, Nottingham, U.K., in 2012.

From 2007 to 2016, he was with the R\&D department, Cummins, Stamford, U.K., first as an Electro-magnetic Design Engineer from 2007 to 2012, and then as a Senior Electromagnetic Design Engineer and Innovation Leader from 2012 to 2016. At Cum-mins, he pioneered the design and development of high-speed electrical machines, transforming a challenging technology into a reliable one suitable for the transportation market, while establishing industry-wide used metrics for such machinery. In 2012, he joined the University of Nottingham as a Senior Fellow in electrical machines, responsible for developing state-of-the-art electrical machines for future transportation that push existing technology boundaries while propelling the new technologies to higher technology readiness levels. He is currently a Chartered Engineer in the U.K.

Zeyuan Xu received the Ph.D. degree in mechanical engineering from the University of Manchester, Manchester, U.K., in 2002.

He was a Research Fellow with the University of Manchester Institute of Science and Technology (UMIST), Brunel University, and the University of Nottingham, Nottingham, U.K. He is currently a Senior Research Fellow in thermo-mechanical design of high-speed electrical machines with the Power Electronic, Machine and Control group, University of Nottingham. His main research interests include turbulent thermo-fluid flow, heat transfer enhancement, and thermal management of advanced electrical machines and power electronics.

Chris Gerada (M'05-SM'12) received the Ph.D. degree in numerical modeling of electrical machines from the University of Nottingham, Nottingham., U.K. in 2005.

He was a Researcher with the University of Nottingham on highperformance electrical drives and on the design and modeling of electromagnetic actuators for aerospace applications. In 2008, he was appointed as a Lecturer in Electrical Machines; in2011, as an Associate Professor; and in 2013, as a Professor with the University of Nottingham. 
He is currently an Associate Pro-Vice-Chancellor for Industrial Strategy and Impact and Professor of Electrical Machines with the University of Nottingham. He has authored or coauthored more than 350 referred publications. He has secured over $£ 20 \mathrm{M}$ of funding through major industrial, European, and U.K. grants. His principal research interest includes electromagnetic energy conversion in electrical machines and drives, focusing mainly on transport electrification.

Dr. Gerada was the Research Chair of the Royal Academy of Engineering in 2013 and also the Chair of the IEEE IES Electrical Machines Committee. He was an Associate Editor for the IEEE TRANSACTIONS ON INDUSTRY APPLICATIONS 